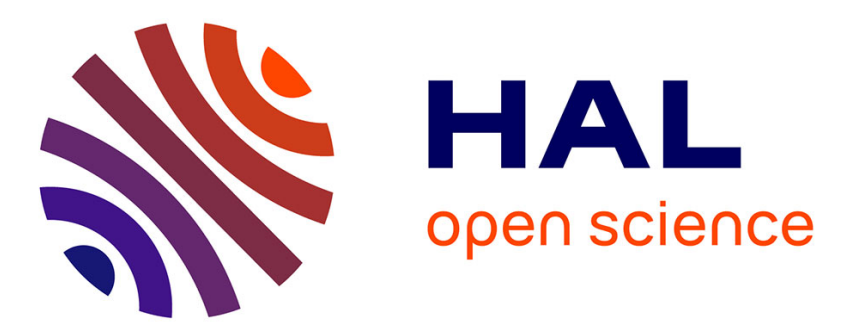

\title{
The influence of traditional medicine and religion on discontinuation of ART in an urban informal settlement in Nairobi, Kenya
}

Christian Jp Unge, Anders Ragnarsson, Anna Mia Ekstrom, Dorcus Indalo, Alice Belita, Jane Carter, Festus Ilako, Björn Södergård

\section{To cite this version:}

Christian Jp Unge, Anders Ragnarsson, Anna Mia Ekstrom, Dorcus Indalo, Alice Belita, et al.. The influence of traditional medicine and religion on discontinuation of ART in an urban informal settlement in Nairobi, Kenya. AIDS Care, 2011, pp.1. 10.1080/09540121.2010.534432 . hal-00677866

\section{HAL Id: hal-00677866 https://hal.science/hal-00677866}

Submitted on 10 Mar 2012

HAL is a multi-disciplinary open access archive for the deposit and dissemination of scientific research documents, whether they are published or not. The documents may come from teaching and research institutions in France or abroad, or from public or private research centers.
L'archive ouverte pluridisciplinaire HAL, est destinée au dépôt et à la diffusion de documents scientifiques de niveau recherche, publiés ou non, émanant des établissements d'enseignement et de recherche français ou étrangers, des laboratoires publics ou privés. 

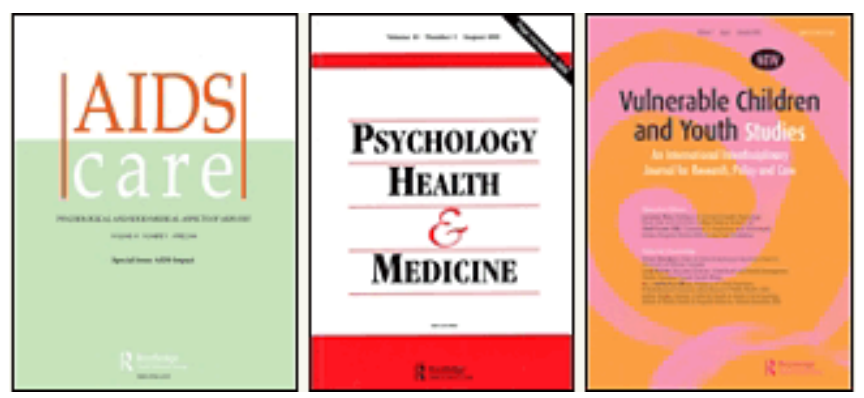

The influence of traditional medicine and religion on discontinuation of ART in an urban informal settlement in Nairobi, Kenya

\begin{tabular}{|r|l|}
\hline Journal: & $\begin{array}{l}\text { AIDS Care - Psychology, Health \& Medicine - Vulnerable Children } \\
\text { and Youth Studies }\end{array}$ \\
\hline Manuscript ID: & AC-2010-04-0191.R2 \\
\hline Journal Selection: & AIDS Care \\
\hline Keywords: & traditional medicine, religion, drop out, HIV, Kenya \\
\hline \multicolumn{2}{|l}{} \\
\hline
\end{tabular}

SCHOLARONE ${ }^{m}$

Manuscripts 
The influence of traditional medicine and religion on discontinuation of ART in an urban informal settlement in Nairobi, Kenya 
Word count: 3305 


\begin{abstract}
Objective

The objective of this study was to explore the influence of traditional medicine and religion on discontinuation of antiretroviral therapy (ART) in one of Africa's largest informal urban settlement, Kibera, in Nairobi, Kenya.

\section{Methods}

Semi-structured face-to-face interviews were conducted with 20 patients discontinuing the African Medical and Research Foundation (AMREF) ART program in Kibera due to issues related to traditional medicine and religion.

\title{
Results
}

Traditional medicine and religion remain important in many people's lives after ART initiation, but these issues are rarely addressed in a positive way during ART counseling. Many patients found traditional medicine and their religious beliefs to be in conflict with clinic treatment advice. Patients described a decisional process, prior to the actual drop-out from the ART program that involved a trigger event, usually a specific religious event, or a meeting with someone using traditional medicine that influenced them to take the decision to stop ART.

\section{Conclusion}

Discontinuation of ART could be reduced if ART providers acknowledged and addressed the importance of religious issues and traditional medicine in the lives of patients, especially in similar resource-poor settings. Telling patients not to mix ART and traditional medicine appeared counter-productive in this setting. Introducing an open discussion around religious beliefs and the 
pros and cons of traditional medicine as part of standard counseling, may prevent drop-out from ART when side effects or opportunistic infections occur.

Key words: traditional medicine; antiretroviral therapy; ART; religion; drop out; HIV; Kenya; Kibera; urban informal settlement; slum; AMREF 


\section{Introduction}

There are specific challenges to sustaining HIV care and treatment programs in informal settlements in sub-Saharan Africa (SSA) given the high mobility, poverty, lack of family support structures, mixed target populations and higher risk behaviors including alcohol and drug use in the populations residing there. However, little research has been conducted on retention in care in African informal settings addressing these challenges (Mills, et al., 2006). A review of 33 African cohort, however none of them in an informal settlement, including over 74,000 patients in 13 countries, found that ART programs had mean retention rates of $79 \%, 75 \%$ and $62 \%$ at 6, 12 and 24 months respectively (Rosen, Fox, \& Gill, 2007). One previous study from an informal settlement in Kenya, found that $29 \%$ of the patients discontinued ART (Unge, et al., 2009).

In SSA up to $70 \%$ of the population uses traditional medicine as the first line medical care (WHO, 2008). In a study by Babb et al (2007) from South Africa, $84 \%$ of the patients on ART were at the same time using traditional medicine (Babb, et al., 2007). UNAIDS states that about $60 \%$ of people in SSA initially visit a traditional health practitioner for treatment of sexually transmitted infections, including HIV (UNAIDS, 2000). UNAIDS has also developed guidelines for collaboration between traditional and conventional (biomedical) medicine (UNAIDS, 2006). Collaboration between these two practices has been initiated in many SSA countries but reservations about the results have been raised (Nyika, 2007). 
The health systems in SSA lack human resources to face the increasing needs to care for people living with HIV (Vassall \& Compernolle, 2006) and the World Health Organization (WHO) has since 1974 acknowledged the importance of traditional health practitioners. WHO has also suggested these practitioners become more involved in standard HIV care. The objective of WHO has been to integrate traditional medicine with national health systems, expand the knowledge base on traditional medicine and promote rational use of traditional medicine (Homsy, King, Balaba, \& Kabatesi, 2004).

Besides traditional medicine, religious activities and beliefs are important components for many people in SSA. In Kenya, 75-80\% of the population is Protestant or Catholic, $10 \%$ are Muslims and $10 \%$ belong to various indigenous religions (PEPFAR, 2007). The use of spiritual healing is not well studied but important to many people in Kenya and significant as part of sexual transmitted disease management in Nairobi (Kusimba, et al., 2003).

Despite the widespread use of traditional medicine and the vast importance of religion on the lives of many people, little is known about its influence on discontinuation of ART in SSA (Wanyama, et al., 2007).

The objective of this study was to explore the influence of traditional medicine and religion on discontinuation of ART in an urban informal settlement in Nairobi, Kenya. 


\section{Methods}

\section{Setting}

This study was conducted in one of Africa's largest urban informal settlement, Kibera, in Nairobi, Kenya. Kibera is the home to 500,000-1,000,000 people. Poverty and unemployment is widespread and most people work in petty trade or as casual laborers (Gulis, 2004). There are many churches and several mosques in Kibera as well as numerous traditional health practitioners.

In 1998, a community-based health clinic was established by the African Medical and Research Foundation (AMREF). Since February 2003, the centre has been providing free HIV treatment, care and support to Kibera residents. By September 2009, the clinic had enrolled 1575 patients on ART.

\section{Explorative study}

An explorative study was conducted in September-October 2008 (unpublished results), in which factors influencing discontinuation of ART were explored using semi-structured interviews with people living with HIV (10 patients) who had withdrawn from the AMREF ART program. The findings from these interviews were discussed in focus group discussions with health care staff at the Kibera clinic (25 staff members in total) (table 1). Due to the focus of this paper these findings will not be discussed in detail. The two main factors influencing retention in care that emerged from this explorative study were traditional medicine and religious issues; therefore we decided to focus on these main topics through another set of semi-structured interviews. 


\section{Inclusion criteria}

Patients who had discontinued ART for reasons related to traditional medicine and religion were identified by community health workers affiliated with the AMREF clinic. The community health workers and social workers were familiar with these patients and hence well aware of the patients' main reasons for discontinuing ART. The patients were thus purposefully selected based on the knowledge of the community health workers/social workers. Informed verbal consent was obtained. Individuals eligible for inclusion in this study were above 18 years of age, had been on ART for at least 4 weeks before discontinuing the ART program and were known to have discontinued ART mainly due to traditional medicine and/or religious beliefs. Discontinuation was defined as not having attended the ART treatment program for 90 days or more (13 months without ART on average).

\section{Data collection}

Data was collected by the first author (CU) together with the fifth author $(\mathrm{AB})$ who speaks English and Swahili and is familiar with the context of Kibera. Most interviews were conducted in Swahili, and, when needed, clarifications made in English. An interview guide was developed in dialogue with social workers, clinical officers and community health workers and tested in two pilot interviews. Minor revisions were made before study start. The interview guide was used to cover relevant issues in the interviews focusing on traditional medicine and religion as reasons for discontinuing ART. 
All interviews were digitally recorded, transcribed verbatim and translated from Swahili to English by AB soon after the interviews. CU reviewed the transcribed interviews and the interviews were then discussed with $\mathrm{AB}$ and clarifications made when necessary.

Twenty-five patients were asked to participate, five declined with no reasons stated. Twenty semi-structured interviews were conducted between March and April 2009 (table 2) that had discontinued the AMREF ART program due to reasons known to be related to traditional medicine and/or religion.

\section{Data analysis}

All the data were analyzed using a qualitative latent content analysis (Elo \& Kyngas, 2008). The transcribed interviews were read numerous times to get a general idea of the material and to discuss the essential characteristics of the text. Coding and categorization were performed in several stages by the first author together with the other co-authors to get better inter-rater reliability. Key words and selected sentences were identified in the text and labeled with codes in the margins. The codes were further compared and grouped together into sub-categories. Finally the sub-categories were compared, regrouped and merged together into more analytical categories (Elo \& Kyngas, 2008). The results were divided into factors patients felt they could influence and those they could not influence, as outlined in the conceptual framework (figure 1).

\section{Ethical approval}

Ethical approval for this study was obtained from the Kenya Medical Research Institute. 


\section{Results}

The influences of traditional medicine and religion on discontinuation of ART were explored and divided in to four main categories: 1) Patients' firm belief in traditional medicine compared to biomedical medicine; 2) Faith, praying and religious practices; 3) Attitudes from church/pastor and 4) Trigger events. The interviewees described a decisional process prior to actual withdrawal from the ART program that involved a trigger event, i.e. a specific event that influenced them to make the actual decision to stop ART.

All patients were living under extremely poor conditions, struggling to find food, overcoming stigma and finding it difficult to disclose their status. Many had been diagnosed with HIV at a late stage, often already showing signs of AIDS. Several of the women were widows and in many cases their husbands had died of AIDS having started ART too late or completely refused treatment at the time of diagnosis. Traditional medicine and religion were key elements in all the interviewees' lives even before being HIV positive and continued to be so also after ART initiation. An important aspect was the fact that the use of traditional medicine, prayers and other religious practices were perceived as factors that the patient could control as compared to many other factors that patients experienced during ART that were perceived to be beyond their individual control, as presented in the conceptual framework (figure 1). Another important finding was that in the minds of the patients, traditional medicine was related to cure and religion was linked to the possibility of getting healed. Both cure and healing were interpreted as the eradication of HIV infection.

Patients'firm belief in traditional medicine compared to biomedical medicine 
The possibility of getting cured by taking traditional medicine was raised as a reason for taking traditional medicine instead of ART (quote 1, table 3). The patients described traditional medicine as something within their own control, something they could choose to take or not. Many patients had taken traditional medicine or sought a traditional health practitioner for care since childhood and this was their usual way of seeking health care.

None of the patients interviewed in this study felt they could discuss traditional medicine openly with the staff at the AMREF clinic. The staff told the patients to never mix ART and traditional medicine and this message was well known to all interviewees. On the other hand, most respondents described how they were strongly encouraged to take traditional medicine by family members or friends (quote 2). Some of the interviewees were even forced by family members to stop ART and start traditional medicine (quote 3). The patients thus had to make one out of three possible decisions: continue taking ART and ignore traditional medicine; take traditional medicine and stop ART; or taking both at once. None of the respondents had revealed their use of traditional medicine to the health care staff at the HIV clinic.

\section{Faith, praying and religious practices}

Religious practices were described at two levels: one personal, related to the amount of praying, and, a second more formal level, linked to religious rituals and visits to different religious institutions. Both of these levels were perceived as being within the control of the patient. Many respondents had a firm belief in God's power to heal them and get rid of the disease. Even patients with deteriorating health often believed that if they prayed more and had more faith in God, they would eventually be guided and helped (quote 4). Many interviewees seemed to doubt 
the effect of ART while they strongly believed in prayers. These patients often referred to stories they had heard or people they knew who had bad experiences of ART (quote 5).

\section{Attitudes from church/pastor}

Since almost all the patients in our study reported going to church or a mosque regularly, the influence of pastors/imams and church/mosque elders was of great importance when facing the challenges surrounding HIV and ART. Some patients expressed fear of the priests' reaction to them being HIV infected (quote 6). Some of the interviewees had seen fellow members of the church being expelled after disclosing their status. The ones that had disclosed their status had sometimes faced negative reactions from pastors and church elders and some had even been forced to leave their congregations.

\section{Trigger events}

Almost all patients described an event that made them decide to stop ART. Often it was meeting with a person who influenced them to discontinue the ART (quote 7). The trigger event was often a religious event, for instance a prayer meeting (quote 8). Often a friend who had positive experiences from praying inspired the patients to discontinue ART (quote 9). 


\section{Discussion}

Traditional medicine has previously been found to be an important factor for low adherence to ART in many African countries (Dahab, et al., 2008) but to our knowledge the relationship between traditional medicine/religion and antiretroviral treatment discontinuation has not been studied.

Our study among urban slum dwellers in Kibera, Kenya, showed that many of the interviewees believed that traditional medicine and/or religion would cure the HIV infection, while ART, at best, would only prolong life. Some even thought that ART could cause premature death.

Most patients in our study reported having tried traditional medicine to get cured from HIV. At the same time, many seemed to know that herbal medicines are less efficient than ART in fighting HIV and that they should not be mixed. Counseling patients to not mix ART and traditional medicine appeared to be contra-productive in this setting. Patients used to taking traditional medicine since childhood might switch from ART to traditional medicine when experiencing side effects or when opportunistic infections occur. These treatment interruptions, not supervised by trained health professionals, could lead to development of resistance due to half-life differences of antiretroviral drugs. The treatment interruptions we noted as a result of the do not mix message could be a more serious threat to public health than possible, but yet unknown, drug interactions between ART and the traditional medicine used in the Kibera slum.

When treating, or counseling patients for any disease, it is important to take the widespread use of traditional medicine into account (Babb, et al., 2007). Since all the patients interviewed in this 
study felt they could not discuss traditional medicine with the staff at the clinic, the importance of open discussions regarding this topic cannot be over-emphasized.

Many interviewees in our study stopped ART and took up praying instead since, as they expressed it, they saw a chance of getting healed through God. When struggling with the challenges related to ART, such as side-effects, enhanced feelings of hunger, and stigma, many chose to put, as they said, their lives in the hands of God, trusting he would make them better or even cure them of HIV infection. Since religion is such an important part of many patients' lives, religious discussions should be included in the day-to-day work of the clinic. Another key issue in this setting is discussion with church representatives about the effects of negative attitudes towards positive HIV status and the importance of taking the ART.

For almost all patients, the final decision to discontinue ART needed a trigger event in this study. We defined a trigger event as an event or a person that influenced the patient fundamentally, something the patient could describe in detail even years later. In many cases it was a friend or a family member who persuaded or inspired the patient to go for traditional medicine or prayers instead of ART. A trigger, or a cue, is a component present in general theories of motivation and change such as the Wellness Motivation Theory (Fleury, 1991) and the Trans theoretical Model of Change (Prochaska \& Velicer, 1997). Trigger events are also part of an HIV-specific theory, as proposed by Enriques et al (Enriquez, Lackey, O'Connor, \& McKinsey, 2004). After a trigger event the patients break their non-adherent behavior. In order for this to happen a process containing five components need to occur: The patients' attitudes towards the treatment need to change, the patient should find the right health care provider, create a support system, gain 
control over life and form goals (Enriquez, et al., 2004). In this theory (Enriquez, et al., 2004), trigger events are assumed to initiate positive health behavior change (Nordqvist, Sodergard, Tully, Sonnerborg, \& Lindblad, 2006). In our study, however, trigger events led to discontinuation of ART and the move to traditional medicine or religion instead of a positive health behavior change.

The importance of collaborating with faith leaders in order to retain patients in ART programs have been raised by other researchers (Roura, et al., 2010). Our study emphasizes the need for health care staff to have a dialogue with patients, and, if possible faith leaders, about having a religious belief while still taking ART.

In SSA, many patients are diagnosed at a very late stage of HIV infection when signs of AIDS are already evident. Late initiation of ART in many low-income countries is a major factor for early AIDS-related mortality (Stringer, et al., 2006). This seemed to be the case for several of our interviewees' husbands who died soon after ART initiation, leaving the women alone to face enormous challenges taking care of children, providing food and, at the same time, fighting their own HIV disease. The late diagnosis - and thus late initiation of ART - probably also influenced attitudes towards ART negatively among the patients in Kibera. According to this study the interviewed patients did not perceive ART as treatment that increased survival, something that traditional medicine and praying were believed to do.

As shown in the conceptual framework (figure 1), according to the interviewees the process from ART initiation to discontinuation was influenced by numerous factors. These could be divided 
into factors within the patient's control and factors that were perceived as outside the control of the patient. Several factors, like food-deficit or the ART side effects were perceived by the patients as being outside their control. On the other hand, what church to attend or what ARV clinic to choose, lies within the control of the patient. According to the patients in this study they needed to somehow get control of their lives before being committed to adhering to the ARV treatment and to stay in the program, something that can be challenging when living in a difficult context like this. This need for control to increase adherence has been previously found in other studies (Sodergard, et al., 2007). Interventions to decrease discontinuation of ART need to focus on the factors that the individual can control, such as the time of diagnosis, by encouraging people to get tested for HIV. Patients initiating treatment should be informed about the possible side effects they could experience. There is also need to influence attitudes towards ART in the community so that patients understand that initiating ART treatment too late may result in the treatment not being effective. It is important to review the information provided at the clinic concerning traditional medicine, as well as having encouraging open dialogue about religious issues.

Social desirability could have influenced the respondents to say things they believed the interviewer wanted to hear. However, measures were taken to limit the risk of such bias. None of the persons carrying out the interviews were AMREF staff and since negative comments were made about the ART program we believe social desirability was limited. It could also be the most motivated patients who accepted to participate in the study and selection bias cannot be ruled out, but we believe that this did not influence the findings since most patients approached accepted to participate in the study. The reason so few men were interviewed was partly a reflection of reality 
since the ratio of women to men followed at the clinic is 2:1 (unpublished data from an ongoing study). Another possible reason was that women were more motivated to participate, according to the community health care workers.

\section{Conclusion}

Discontinuation of ART could be reduced if ART providers become better at acknowledging and addressing the importance of religious issues and traditional medicine in the lives of patients, especially in resource-poor settings where stigma, poverty and lack of food and social support are key elements in the lives of HIV patients. An open, non-judgmental, discussion around patients' beliefs and practices as part of standard counseling would make patients more comfortable to discuss doubts with the staff before discontinuing ART. Patients should be informed that some traditional medicine is possible to combine with ART and that religious beliefs are not in contradiction with ART. Peer groups could be used to prepare patients for common trigger events that have caused others to discontinue treatment. Counseling patients not to mix ART and traditional medicine appeared to be counter-productive in this setting since patients are used to taking traditional medicine and might switch from ART to traditional medicine when experiencing side effects or when opportunistic infections occur. Further research is needed on the possible interactions between commonly used traditional medicine and ART. 
Table 1. The main factors influencing discontinuation/retention in care, as stated both by patients and staff at the AMREF clinic.

- Support from church/faith

- Healing and traditional medicine

- Support from health-staff

- The preservation of own and family's health

- Bad attitude among health staff

- Stigmatisation in society

- Food insufficiency

- Side effects 
Table 2. Demographics of patients having discontinued antiretroviral treatment due to reasons related to traditional medicine and religion from the AMREF clinic, Kibera, Nairobi, Kenya.

\begin{tabular}{|c|c|c|c|c|c|}
\hline Age & Sex & Tribe & Civil status & Religion & Work \\
\hline 1 & $28 \mathrm{~F}$ & Luo & Married & Protestant & Unemployed \\
\hline 2 & $36 \mathrm{~F}$ & Kisii & Widow & Catholic & Business \\
\hline 3 & $40 \mathrm{~F}$ & Luo & Widow & $\mathrm{SDA}^{*}$ & Unemployed \\
\hline 4 & $40 \mathrm{~F}$ & Kamba & Widow & Protestant & Business \\
\hline 5 & $27 \mathrm{~F}$ & Luo & Single & Protestant & Business \\
\hline 6 & $29 \mathrm{~F}$ & Luo & Married & Protestant & Unemployed \\
\hline 7 & $40 \mathrm{~F}$ & Nubian & Divorced & Muslim & Unemployed \\
\hline 8 & $44 \mathrm{~F}$ & Luya & Widow & Protestant & Unemployed \\
\hline 9 & $28 \mathrm{~F}$ & Luya & Married & Muslim & Unemployed \\
\hline 10 & $52 \mathrm{M}$ & Luya & Married(Polygamos) & Protestant & Herbal shop \\
\hline 11 & $40 \mathrm{~F}$ & Luya & Separated & Muslim & Business \\
\hline 12 & $40 \mathrm{~F}$ & Luo & Widow & Protestant & Business \\
\hline 13 & $32 \mathrm{~F}$ & Luya & Married & Protestant & Unemployed \\
\hline 14 & $37 \mathrm{M}$ & Kisii & Married & SDA* & Security \\
\hline 15 & $50 \mathrm{~F}$ & Kamba & Widow & Catholic & Business \\
\hline 16 & $36 \mathrm{~F}$ & Luya & Widow & Catholic & Unemployed \\
\hline 17 & $43 \mathrm{~F}$ & Luo & Married & Protestant & Business \\
\hline 18 & $37 \mathrm{~F}$ & Luo & Widow & Catholic & Unemployed \\
\hline 19 & $32 \mathrm{~F}$ & Luo & Widow & Protestant & Hairdresser \\
\hline 20 & $36 \mathrm{M}$ & Meru & Married & Protestant & Watchman \\
\hline
\end{tabular}

$* \mathrm{SDA}=$ Seventh Day Adventist 
Table 3. Categories and quotes from the interviews with patients discontinuing antiretroviral treatment in the Kibera slum due to reasons related to traditional medicine and religion.

\begin{tabular}{ll}
\hline Category & Quotes (\#) \\
\hline Patients' firm belief in & (1) If you use them (herbs) properly there is a possibility of getting cured \\
traditional medicine & ... According to what I have heard about the ART it is possible that the \\
compared to & viral load might be undetectable but still the virus will be in the body. (P \\
biomedical medicine & 2)
\end{tabular}

(2) I was living with my grandmother who is a herbalist. She told me to use the herbs because they are safer than the other medicine. She said the ART have chemicals that affect the body but the herbs are natural. (P 5) (3) My mother forced me to use the traditional medicine ... She just told me to use the traditional medicine because it is good ... She told me that she gives the herbs to other people and they get well ... I told her that I was using ART but she told me to stop and use the herbs. (P 6)

Faith, praying and (4) Even if one uses medication but they do not believe in God they cannot religious practices get well. I believe that God is capable of healing any person whether they are using medication or not. I would rather believe in God and go on with my life and take care of my children ... Prayer only is enough. When I was very sick I was prayed for and I even got better before I started taking ART. Even if I did go to hospital, I believe that the prayers helped. Even those that pray do go to hospital. (P1)

(5) I stopped using the ART because of prayers. Also because I have two other friends that are HIV-positive but one died yet she was using ART, I do not know what was wrong that made her die. I am not using ART, I just pray and I am alive and well. (P 11)
Attitudes from
(6) I have not disclosed to any priest because they always come and go.
church/pastor
They are usually transferred; they are not permanent. There are some church elders but they are not that perfect. You may tell them, but they may end up announcing it to the church or to other people. Even with the priest you have to weigh the option and see if he can keep your secret and 
then you can disclose to him. (P 14)

Trigger events

(7) He (a friend) was also HIV positive and so when he was taking the traditional medicine and saw the changes, he told me. So he is the one who made me stop taking the ART because I saw the changes and he was much better and healthier than before. (P 18)

(8) They said that those who are infected with HIV are healed. They also said that those who were in that meeting and were using the ART should stop because they are healed. (P 13)

(9) I saw a friend of mine who had gone for prayers somewhere. She explained to me and asked me to go for prayers with her. I followed her and I saw people who were being prayed for and they even stopped using ART. I then decided to do as they were doing. (P 9) 
Figure 1: Conceptual framework. Factors influencing the patients' decision to discontinue ART.

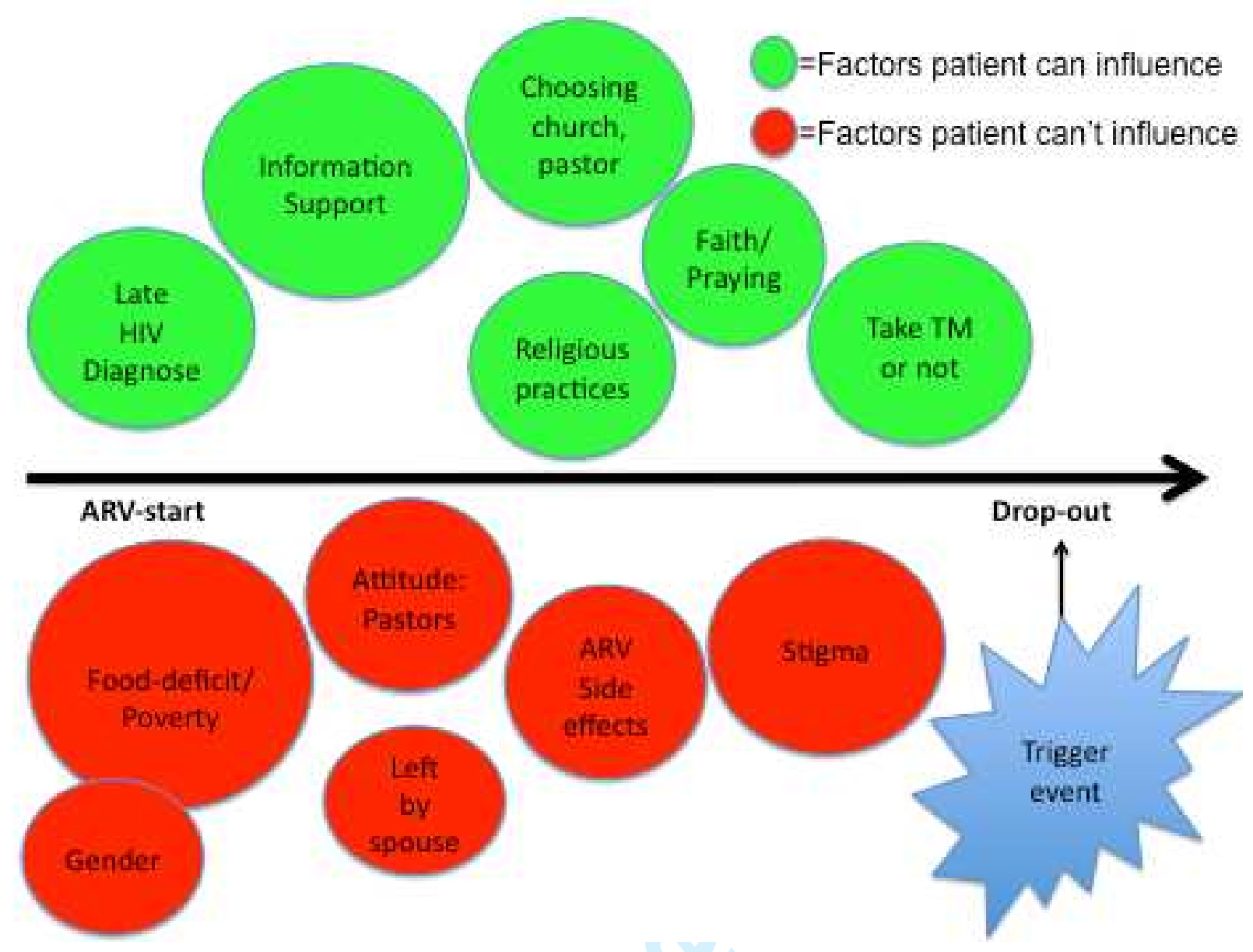




\section{References}

Babb, D. A., Pemba, L., Seatlanyane, P., Charalambous, S., Churchyard, G. J., \& Grant, A. D. (2007). Use of traditional medicine by HIV-infected individuals in South Africa in the era of antiretroviral therapy. Psychol Health Med, 12(3), 314-320.

Dahab, M., Charalambous, S., Hamilton, R., Fielding, K., Kielmann, K., Churchyard, G. J., et al. (2008). "That is why I stopped the ART": patients' \& providers' perspectives on barriers to and enablers of HIV treatment adherence in a South African workplace programme. BMC Public Health, 8, 63.

Elo, S., \& Kyngas, H. (2008). The qualitative content analysis process. J Adv Nurs, 62(1), 107115.

Enriquez, M., Lackey, N. R., O'Connor, M. C., \& McKinsey, D. S. (2004). Successful adherence after multiple HIV treatment failures. $J$ Adv Nurs, 45(4), 438-446.

Fleury, J. D. (1991). Empowering potential: a theory of wellness motivation. Nurs Res, 40(5), 286-291.

Gulis, G. (2004). Health status of people of slums in Nairobi, Kenya. Environmental research(96), 219-227.

Homsy, J., King, R., Balaba, D., \& Kabatesi, D. (2004). Traditional health practitioners are key to scaling up comprehensive care for HIV/AIDS in sub-Saharan Africa. Aids, 18(12), 1723-1725.

Kusimba, J., Voeten, H. A., O'Hara, H. B., Otido, J. M., Habbema, J. D., Ndinya-Achola, J. O., et al. (2003). Traditional healers and the management of sexually transmitted diseases in Nairobi, Kenya. Int J STD AIDS, 14(3), 197-201.

Mills, E. J., Nachega, J. B., Bangsberg, D. R., Singh, S., Rachlis, B., Wu, P., et al. (2006). Adherence to HAART: a systematic review of developed and developing nation patientreported barriers and facilitators. PLoS Med, 3(11), e438.

Nordqvist, O., Sodergard, B., Tully, M. P., Sonnerborg, A., \& Lindblad, A. K. (2006). Assessing and achieving readiness to initiate HIV medication. Patient Educ Couns, 62(1), 21-30.

Nyika, A. (2007). Ethical and regulatory issues surrounding African traditional medicine in the context of HIV/AIDS. Dev World Bioeth, 7(1), 25-34.

PEPFAR (2007). Kenya profile. http://www.pepfar.gov/documents/organization/101657.pdf

Prochaska, J. O., \& Velicer, W. F. (1997). The transtheoretical model of health behavior change. Am J Health Promot, 12(1), 38-48.

Rosen, S., Fox, M. P., \& Gill, C. J. (2007). Patient retention in antiretroviral therapy programs in sub-saharan Africa: a systematic review. PLoS Med, 4(10), e298.

Roura, M., Nsigaye, R., Nhandi, B., Wamoyi, J., Busza, J., Urassa, M., et al. (2010). "Driving the devil away": qualitative insights into miraculous cures for AIDS in a rural Tanzanian ward. BMC Public Health, 10, 427.

Sodergard, B., Hofer, S., Halvarsson, M., Sonnerborg, A., Tully, M. P., \& Lindblad, A. K. (2007). A structural equation modeling approach to the concepts of adherence and readiness in antiretroviral treatment. Patient Educ Couns, 67(1-2), 108-116.

Stringer, J. S., Zulu, I., Levy, J., Stringer, E. M., Mwango, A., Chi, B. H., et al. (2006). Rapid scale-up of antiretroviral therapy at primary care sites in Zambia: feasibility and early outcomes. Jama, 296(7), 782-793. 
UNAIDS (2000). Collaboration with traditional healers in HIV/AIDS prevention and care in subSaharan Africa A literature review. http://data.unaids.org/Publications/IRC-pub01/JC299TradHeal_en.pdf

UNAIDS (2006). Collaborating with Traditional Healers for HIV Prevention and Care in subSaharan Africa: suggestions for Programme Managers and Field Workers.

Unge, C., Sodergard, B., Ekstrom, A. M., Carter, J., Waweru, M., Ilako, F., et al. (2009). Challenges for scaling up ART in a resource-limited setting: a retrospective study in Kibera, Kenya. J Acquir Immune Defic Syndr, 50(4), 397-402.

Vassall, A., \& Compernolle, P. (2006). Estimating the resource needs of scaling-up HIV/AIDS and tuberculosis interventions in sub-Saharan Africa: a systematic review for national policy makers and planners. Health Policy, 79(1), 1-15.

Wanyama, J., Castelnuovo, B., Wandera, B., Mwebaze, P., Kambugu, A., Bangsberg, D. R., et al. (2007). Belief in divine healing can be a barrier to antiretroviral therapy adherence in Uganda. AIDS, 21(11), 1486-1487.

WHO (2008). Traditional Medicine Fact Sheet, from http://www.who.int/mediacentre/factsheets/fs134/en/print.html 